\title{
Editorial
}

\section{Migration, Youth and Children: An Introduction}

\author{
Beatrice Okyere-Manu \\ ORCID iD: https://orcid.org/0000-0003-2735-9227
}

\section{Herbert Moyo \\ ORCID iD: https://orcid.org/0000-0001-9648-9426}

\section{Introduction}

Human beings are mobile entities, and in recent years we have experienced large movements and migrations of people in different parts of the world. Studies have shown that Migration, be it international, continental or urban have positive and negative implications for the sending and receiving, communities. Even though there are different reasons why people move, most of them are linked to economics and development. Most scholars for that matter, emphasis has been put on migrants' remittances (Page \& Adam 2004; Lazcko 2005; Adepoju 2007). To this end, a number of studies claim that Migration has benefited most developing countries especially because of the volume of remittances flowing into the sending countries. Migration at the household level, is also essential both as a livelihood enhancement strategy and a means of mitigating against vulnerabilities in times of economic hardships (Quartey 2006; Awumbila \& Ardayfio-Schandorf 2008).

Despite the positive effects of migration, a number of scholars have noted the numerous consequences of migration on those left behind especially grandmothers, children and the youth in the process of migration. It is assumed that, children and youth are caught up in the dynamics of the migration of their parents and or guardians (Rossi 2008; Rossi et al. 2002). 
A number of children are often separated from their parents (one or both parents) during the process of migration, due to the un-coordinated, if not chaotic nature of migration, or because of international states or nation-state conditions and agreements. Whereas some Scholars argue that children adjust well after separation from their parents (Coe 2008), a growing number of scholars have noted the negative consequences migration has on children and youth, for instance, words such as 'plight' have been used to describe their predicaments (Yeoh \& Lam 2006; Reyes 2007). In most instances, young people have felt abandoned and as a result have blamed their parents for even their poor performances academically, general health and wellbeing. In addition, social behaviour, relationships and the socialization of children are affected negatively, also the reorganisation of familial environment and roles negatively affect the children and youth left behind in their upbringing (SuarezOrozco et al. 2002; Whitehead et al. 2005).

On the other hand. Children and youth that happen to travel with their parents also experience the same challenges experienced by adults. In most instances, their experiences of migration are quite unsettling. They are often challenged psychologically, socially, culturally and religiously, if they are not confused, or bewildered (Hlatshwayo et al. 2014; McKenzie 2011). Children end up in the receiving country as undocumented illegal residents (Skelton et al. 2014), while some are documented as aligned with the registration processes their parents have to go through. Children - whether legal or illegal - may also experience forms of challenges related to hospitality and/ or forms of alienation and even xenophobia in their receiving communities, and all these experiences impact their lives for better or worse, for most of their lives.

In this special issue Africans Scholars are reflecting on the various forms of the articulation of the impact(s) of migration on children and the youth from an African perspective. The contributors to this special edition, can be categorize into three groups, most of them are Africa migrants themselves who have and continue to experience some of the challenges described above. Others have not migrated; however, they are familiar with the dynamics describe above. The third group are migrants who have managed to go through these challenges. The contributors therefore write from either insiders or outsiders perspective.

The contributions do not only indicate the hopes and aspirations, but also the stresses and strains of migration. They also explore the experiences of children and youth involve in migration either in their host countries as left 
behind or in their new countries of adoption, and settlement. Through the different methodologies employed, this special edition opens up possibilities for intervention in areas of conflict, stresses and strain.

\section{Summary of Contributions to this Issue of Alternation}

The articles in this special issue are not set in a particular order however they speak to one core issue, migration and children. As noted above the articles have engaged issues such as identity, human rights of children, the immigration laws and home affairs systems in South Africa and the politics of Zimbabwe that produce so much migrants running away from poverty and political violence. The first article is titled: 'Where Thunder Goes to Die: Exile and Frustration of Migration in Esiaba Irobi's Poetry', by Niyi Akingbe. The article analyses the clash between expectation and reality of failure suffered by Esiaba Irobi, when he fled the frustration and persecution at home in Nigeria, to the United Kingdom on the British Foreign and Commonwealth Office Fellowship in 1989. This a poetic paper about Irobi who is a vibrant Nigerian youth and his (mis)adventures in the United Kingdom when he suffered alienation as an aftermath of racism. He sojourns in America and eventual died in a German hospital reflecting the trajectory of Nigerian youth migration. These difficulties apparently manifested in Irobi's failure to secure tenured job. He experienced persistent rejection of his manuscripts by publishers and also failed to secure an appreciative audience for his literary works which eventually diminished his talent as a burgeoning African poet and playwright. Stricken with a sense of failure as an aftermath of the accrued frustrations, his health was damaged which later resulted into his untimely death. This article frames what many young migrants experience in the diaspora.

The article by Mpumelelo Moyo directly points out to the term used to label foreign nationals in South Africa especially those who speak languages that are not familiar in eMzansi (South Africa). The term amaKwereKwere has become a form of identity for foreigners. The article is titled "Kwerekwere" or Zimbabwean? A Burden of Identity for Zimbabwean Youth in South Africa'. The research involved 29 youths who responded to questionnaires and interviews over the telephone and social media. It investigated the impact of migration, the media, attitudes and socialization experiences, shaping Zimbabwean youths living in South Africa. The study found that life in South African Diaspora has many opportunities but also challenges for the youth, 
among them a crisis of identity. Many of the areas in which they live in Gauteng are closed communities in limbo dominated by adult connections and interactions. Whereas many of the youths who participated in the study grew up in South Africa and were educated in South African schools, they felt neither South African nor Zimbabwean. For many of these youths, their experience of Zimbabwe is very limited and that of South Africa broader than that of their parents, creating a rift and conflicts with the latter yet they are still labelled as 'kwerekwere' by South African counterparts.

The identity crisis experienced by the youth in South Africa is similar in many ways to identity crisis experienced by Zimbabwean youths who live in the United Kingdom. This is well explained by Nomatter Sande and Daniel Manyanga whose paper is titled 'Youth Identity Crisis in the Diaspora: Christian Zimbabweans in the United Kingdom'. The Findings of their article posits that culture, parental relationships, belongingness, social pressures, self-image and church are factors that influence the identity crisis of the youth in diaspora. Using a case study, the article contributes to the understanding that migration processes cause the youth (second generation) to have 'hybrid identities' while parents (first generation) have 'dual identities'. They further, challenged the that church in order to restore the identity of the youth, they should use the identity theology which emphasises 'sameness', 'renewal of mind' and 'belonging'.

The youth of Zimbabwe and young children born in South Africa are stateless as they neither belong to Zimbabwe nor South Africa. This is the article by Herbert Moyo. It is titled: 'Zimbabwean Illegal Migrants in South Africa and the Problem of Stateless Children'. Moyo argues that the Illegal crossing of the border between Zimbabwe and South Africa along the Limpopo River and at the Beitbridge border post has become a daily reality. Zimbabweans are pushed by the economic crisis to seek for jobs and commodities in South Africa. The article concludes that children are innocent victims of the sins of their parents. There should be a change of policy on citizenship both in Zimbabwe and South Africa to protect the human rights of children who are victims of circumstances beyond their own control. It further recommended a new reforms in citizenship laws in Southern Africa. To avoid the incidence of children of illegal migrants becoming stateless, states in Southern Africa should enact a law of citizenship by birth. Children born in a particular country should become citizens of that country regardless of the citizenship status of the parents. 
Laureen Confait and Federico Settler on 'Parenting, Identity and Children's Spirituality in Ethiopian Orthodox Migrant Households in South Africa' deals with issues of identity for the Ethiopian Tewahedo community in South Africa. The article is related to Sunde and Manyanga's paper as it points to hybrid identities by the youth in the Ethiopian Tawahedo community. It argues that social isolation, cultural and linguistic challenges are the key issues faced by migrant parents in developing their children's religious, cultural and social identity. The article shows that a range of transnational religio-cultural strategies and resources are used to mitigate such challenges, and migrant parents utilise such resources in their efforts to help their children to navigate religious and social relations.

Beatrice Okyere-Manu writes on 'Negotiating Identity and Belongingness as Migrant Youth: The Chameleon and the Butterfly Strategies'. Okyere-Manu argues that contrary to the popular assertion that migrant youth live in two cultural worlds that is: the country of origin of their parents and the host country, there is a third world which is as influential as the two worlds. She identified the third world as the home where the youth reside with their parents in the host country. This suggests that they face tri-cultural based conflict which influences their identity. The inference here is that their identities are shaped by the host country, their country of origin and the hybrid culture in their home where they reside with their parents in the host country. She further argues that despite the challenges they face in these three worlds, some of them are able to develop strategies such as the chameleon and the social butterfly strategies to enable them to cope with the expectations of the three worlds.

Sophia Chirongoma titled her paper, 'Neither Here nor There: The Experiences of Zimbabwean Migrant Children and Youth'. Chirongoma's paper is an auto- ethnographic exploration of how migration presents numerous adjustment challenges for Zimbabwean migrant children and youth. It illuminates the various 'push' and 'pull' factors for migrating from Zimbabwe. Chirongoma concludes that the escalating unemployment rates have forced most of the Zimbabwean youth to migrate in search of employment. Consequently, children and youth from Zimbabwe have had to contend with various impacts of these migration trends.

In a context of forced migrations in Zambia, Nelly Mwale argues that Catholic Based Organisations are making a modest contribution to the welfare of the refugee youth population. The article titled 'The Role of Catholic Based 


\section{Organisations in Addressing Livelihood Challenges of the Rural Youth} Population in the Context of Forced Migration in Zambia' exposes the experiences of migrant youths in Zambia. It argues that while religion and forced migration are often linked based on the migrant's use of religion, the Zambian context also pointed to how the Catholic Based Organisations could be resourceful in addressing the livelihood challenges among the refugee youth rural population.

Buhle Mpofu's paper is titled 'Navigating Changing Cultural Landscapes: A Quest for Identity and Belonging among Migrant Adolescents in Pietermaritzburg, South Africa'. The paper highlights the different approaches and a range of disciplinary perspectives, objectives, methods and theoretical underpinnings which characterise the discipline of children and youth migration studies. The article employs the bi-acculturation theory to highlight formation processes for migrant adolescents as embodied in fashion and hairstyling practices, language/accent/naming, food cultures, and religious association and music. The article concludes that these symbolic practices are intricately interwoven with the lived experiences of young migrants, and their quest for identity and belonging in in the diaspora.

The next paper by Sinenhlanhla Chisale describes the survival strategies employed by adolescent girls in the diaspora. The title of the article is 'Masihlalisane ${ }^{1}$ Marriages as Migrant Adolescent Girls' Survival Strategy in South Africa: An African Feminist Practical Theological Response'. The identified strategies are relative in nature as they can be dangerous or liberative or both as the case may be. The article posits that young women engage in marriages of convenience to survive in the diaspora. This kind of marriage is commonly known as omasihlalisane in Nguni languages and vaten-sit in Afrikaans. The masihlalisane is assumed to be a marriage of convenience between adults, but the realities of migration have introduced cohabitation unions where refugee minors are forced to lie about their age, in order to benefit from this kind of marriage. Cohabitating between an adult and a

1 The term 'omasihlalisane' refers to cohabitation or 'vat-en-sit' marital unions where two unmarried people live together and conduct their relationship like a married couple. This marital union is a reality in Southern Africa, particularly in South Africa within the migrant population from other countries. It also includes South Africans who migrate from rural areas into cities or urban areas in search for economic opportunities. 
minor has strong criminal and ethical implications, particularly with regard to sexual violence. Informed by an African feminist practical theological approach, this study seeks to highlight a that issue that if the church in Africa wishes to contribute to achieving an ethical and moral regeneration where marriage conforms to Christian and African values and norms.

Bekithemba Dube's paper is titled, 'Struck from all sides' Reliving the Lived Experiences of Immigrant Youths in the Context of Mafiarised Religions: Towards a Rehumanisation of Theology'. Dube interrogates various trajectories in relation to religious mafia faced by undocumented immigrant Zimbabwean youths in the city of Johannesburg. Religion has come to offer solace to migrant youths, since it is has the impetus to usher in 'hope' and quick solutions in the face of a variety of ambivalences and ambiguities. While this religious task may be noble, and desirable, many migrant youths have fallen victim to religious mafia movements, which the paper unmasks and challenges, with the aim of reconstructing a religion that opposes oppression and criminality. Dube concludes the paper by arguing that there is a need to reconstruct a theology that rehumanises oppressed migrant youths, and oppressors, through a deliberate challenge of the religious mafia.

Migrant children have a common challenge when it comes to schooling. Nithi Muthukrishna, Kubendri Maduray and Susan Philpott write about 'Schooling Spaces of African Migrant Children: Vulnerability, Agency and Resiliency'. This article delves into the schooling experiences of African migrant children in the province of KwaZulu-Natal. The findings revealed that African migrant students are able to actively evaluate and construct meanings around their experiences within schooling spaces in a South Africa context. They are active agents in the construction and negotiation of their own specialities. Students view their cultural and social capital as an advantage in their social lives and in achieving academic goals. Networks of support are formed to create a positive schooling experience. It is noteworthy that teachers in the schooling context are portrayed as caring, empathetic and supportive in the narratives of the migrant learners. Although there are no evidence of teachers being complicit in and acting as agents of oppression, the school as an institution is not proactive in addressing oppression and discrimination, partly due the subtle nature of prejudice and discrimination and the silences on the part of the migrant learners.

Raphael Nhongo and Primrose Baba Tshotsho study titled, 'Migra- 
tion, Culture, Child Socialisation and Changing Family Roles and Relations in Bulawayo, Plumtree and Kezi, in Zimbabwe'. Nhongo and Tshotsho acknowledge that the economic crisis in Zimbabwe since 2000 has forced many the people from Zimbabwe to be scattered all over the world mainly in search of employment in countries that include South Africa, Botswana, Namibia, Britain, Australia and the United States of America. The paper therefore scrutinises how this migration of the Zimbabwean people to other countries has impacted on the socialisation of children, roles in the family, relations in families and the Ndebele people's culture in general. The paper concludes that in the socialisation of children, gender also plays a pivotal role because there are different areas where children need specific and special attention in their socialisation. While it is acknowledged that in the contemporary society family structures have changed, it is the idea of this paper that gender roles complement each other in a 'proper' African family set up and where a spouse is not available life becomes abnormal.

Kudzayi Savious Tarisayi and Sadhana Manik's contribution is titled: 'From Periphery to Epicenter: The Resilience of Zimbabwean Immigrant Children despite "Walking a tightrope". This paper discusses the experiences of the children of Zimbabwean teachers who work in South Africa. The findings highlight parental support and a hope for their children being bicultural in South Africa. However, migrant children encounter language barrier at school, and are subjected to humiliation due to their underdeveloped social capital. Nevertheless, they demonstrate that they are sufficiently malleable with great expectations for achievement. They accumulate sufficient socio-cultural capital to assimilate garnering respect, admiration and confidence and to become high academic achievers.

Tenson Muyambo writes on 'Children, Youth and Migration in Zimbabwe: An Indigenous Knowledge Systems Perspective'. Using observation, in-depth interviews and available literature, the paper focuses on the impact of migration on children and youth who remain behind when their parents and guardians emigrate. It argues that the challenges that the youth and children face could be minimised by tapping into ruzivo rwevanhu (people's indigenous knowledge systems).

The following article by Wonder Muchabaiwa discusses 'The Diaspora Phenomenon and the Welfare of Children Left Behind: A Child Rights Approach and Gender Perspective'. This study explores circumstances of children left by migrant parents and how the girl child in particular 
becomes more vulnerable to abuse. The in-depth interviews revealed that children left in the care of family members live under difficult and abusive circumstances. In many cases, the girl child assumes the role of a maid the moment her parents cross the borders. She assumes the responsibilities of running the home which tends to compromise her studies. The study also revealed that some daughters of migrant parents fall pregnant while some become victims of child marriage pointing to the gullibility of girl children in such circumstances. The study concludes that, although children growing in foreign land have their challenges, it is commendable for migrant parents to take their children with them since best child care can be realized under the custodian of parents.

Martin Mujinga writes on 'Derailed by the Greener Pastures? A Socio-Cultural and Religious Dilemma of the Youth in Epworth Circuit of the Methodist Church in Zimbabwe'. Mujinga's article resonates with Wonder Muchabaiwa's contribution. Mujinga's article argues that migration to South Africa is caused by untold suffering because of economic and political conditions in Zimbabwe. People are forced to take the illegal route and cross the Limpopo River illegally. Some parents are not able to travel with their children and as a result creating single parenthood or child headed families in Zimbabwe. The children left behind often have financial support from parents without parental guidance. Parents are often present through money and not physical. Some children are left in the custody of relatives, with some taken to boarding schools. Using semi-structured and focus group interviews, Mujinga argues that the search for greener pastures by most parents derailed their children with some dropping from school. A number of them engage in drug abuse and prostitution still more, others become child headed families. The paper concludes by challenging the Methodist Church in Zimbabwe in Epworth to be relevant in the context of forced migration.

Closely related to Mujinga's article is Canisius Mwandayi's paper is titled, 'Beckoning 'greener pastures' and Imagining 'home': Appropriating and Rubricating Psalm 137 to Explore the Lived Experiences of Diasporic Zimbabwean Youths'. Mwandayi argues that Zimbabweans in the diaspora wish to return to Zimbabwe as soon as the country stabilizes both economically and politically. His argument is based on the analysis of the type of songs people in the diaspora sing which are similar to songs sung by Israelites such as Psalm 137 verse 4 . As the yoke of the foreign Babylonian domination weighed on the exiled Judeans, music became 
one of the ways to let off their tension. Though they could not sing the songs of the Lord (Psalm 137:4) they composed lyrics about their depressing conditions. These lyrics also reminded them of their homeland: Zion. Using hermeneutics of identification whereby readers identify themselves with the biblical characters and culture, this article equates the experience of Judeans with the experience of most Zimbabwean youths in the diaspora due to the worsening economy spanning from the Mugabe era up to the new dispensation under Mnangagwa. Though the migration of most Zimbabweans into the diaspora is not a result of foreign domination; they too long to return home one day. Just like the Israelites, some exiled Zimbabwean singers have also come to compose lyrics which express their pain in the diaspora and their longing to return to Zimbabwe. Songs that resonate with the experiences of Zimbabwean youths are: 'Ndangariro' by the veteran musician Thomas Mapfumo, 'Ndofamba nediaspora' and 'Hatina rugare muZimbabwe' both by the protest musician Viomak. It is against this almost identical situation that this paper appropriates and rubricates Psalm 137 in order to explain the pain and longing felt by most exiled Zimbabwean youths.

Peter Masvotore's article is on 'Lost Identities: Youth Migration and Dispossession in Zimbabwe'. Masvotore's paper is a historical analysis of the ways in which poor dispossessed Zimbabwean youths are coerced to migrate. It argues that the dispossession and attendant migration leave most of the youth without knowledge of their identity that would have guided them into responsible citizenship in Zimbabwe. The article concludes by outlining key lessons that may be learnt from Zimbabwe. These lessons include the need to redress colonial dispossession of Zimbabwean land, and the need not to simplistically condemn youths as aggressive, without factoring the neocolonially induced unbearable hard-ships that they face and that incline them to survivalist violence.

The following article is by Muko Cyril Keba who writes about 'Roles and Obligations of Individual States Towards Migrating Children and Youth: An African Ethics of Hospitality and Responsibility'. Keba Muko says that human crisis of recent waves of forced, sometimes deliberate mass movements of migrants from Africa and other different parts of the world converging to the western countries. Those movements have sometimes caused hosts of casualties, imprisonments, rejections, discriminations, enslavement, alienation and dehumanization of migrants. All these happen despite the common humanity evidently shared and experienced by all rational creatures 
living the common space that is known as mother earth given to the care of the entire human race. The paper concludes that that African ethics of hospitality and an ethics of responsibility can be the bedrock of an effective foundation of the roles and obligations of individual states in the good management of migration of children and youth within the one common planet earth, a home land of all its inhabitants.

\section{Conclusion}

Zimbabwe is seemingly a leading country in Southern Africa in producing migrants to its neighbours. Fourteen of the articles directly talk about migrants from Zimbabwe. Nine of the articles acknowledge that the majority of the migrants are illegally staying mainly in South Africa. The articles are lamenting the political situation in Zimbabwe that has resulted in downward spiralling economy. Zimbabwean youths and children find their way into South Africa mainly with illegal means there by putting their loves in danger. There is also a high level of human trafficking of children into Gauteng. The articles show that the main source of the problem of refugees is poverty because of high unemployment in Zimbabwe. Another challenge is the birth of stateless children in South Africa and elsewhere by Zimbabweans (see Herbert Moyo's article). Four of the papers have highlighted the plight of women and the girl child in the diaspora. These Zimbabweans have come up with several survival skills the majority of which are illegal such as obtaining fake South African identification documents, getting such documents through illegal means, indulging in the sex industry, dealing in drugs and participating in crime. The articles have also highlighted the challenges faced by those who try to get identification documents such as work permits through the legal route. It seems at the moment it is faster and less demanding to get South African identification documents and permits through illegal means than through legal means. The difficulties associated with attaining legal documents are fuelling the corruption around the attainment of documents.

In order to reduce the scourge of illegal immigrants in South Africa there is need to relax immigration laws. The majority of illegal migrants seemingly started through the legal route but the demands are always too much while corrupt authorities dangled a carrot in the form of a corrupt easier and faster route to obtain the same documents. Some interviewees in the articles have applied for ID documents and are waiting for 2 to 3 years to get a positive 
response from the Department of Home Affairs.

Zimbabwe must play its part by changing the political system that is driving its own citizens to the diaspora. The human rights abuses, corruption, unemployment, the lack of a reliable stable currency and many other challenges have created a serious economic and political crisis that needs the United Nations, The African Union and the South African Development Communion should play a leading role in calling the political leaders in Zimbabwe to a negotiating table solve the political crisis. If this is not done successfully, I think in the next few years Zimbabwe will be a province of South Africa. Zimbabweans will keep coming to South Africa for livelihoods. Zimbabweans have some historical links with South Africa especial with the Ndebele people whose History links them to the Zulu hence the majority of these people are quick to think of South Africa than other countries. Zimbabweans share a number of languages with South Africa such as Ndebele (a dialect of Zulu), Sotho, Sepedi, Venda, Shangani, Sibirwa and Xhosa. Zimbabweans belonging to these language groupings can easily hide among the people of their language.

Eight articles engage the plight of the youth in South Africa. It is worth noting that six of the articles deal directly with the experiences of the youth in South where there are challenges ranging from lack of documentation, identity issues, lack of access to educational institutions and easy access to drugs. The articles that mention South Africa also point to legal issues that affect children who are refugees such as being caught up in the sins of their parents especially mothers to the extent of being separated from their parents when parents are arrested and deported. The argument is that the rights of children are negatively affected when parents are migrants. Besides rights, children end up without a specific culture as most of them live in two worlds, the home country and the culture of the country of refugee. Chirongoma says these youth are 'Neither here nor there' while other scholars like Settler and Lareen, Okyere-Manu and Mpofu engage issues of identity from a socio-economic, spiritual and cultural perspectives.

In conclusion, all the articles point to the challenges and opportunities faced by Children and the youth in migration scenarios. In cases where there are challenges that infringe on human rights of children and the youth articles have made some proposals for redressing the situation such as changes in legislation or proper application of existing laws to protect young migrants in particular and migrants in general. 


\section{References}

Adepoju, A. 2007. Migration in sub-Saharan Africa. A Background Paper Commissioned by the Nordic African Institute for the Swedish Government White Paper on Africa.

Awumbila, M. \& E. Ardayfio-Schandorf 2008. Gendered Poverty, Migration and Livelihood Strategies of Female Porters in Accra, Ghana. Norwegian Journal of Geography 62,3: 171 - 179.

https://doi.org/10.1080/00291950802335772

Coe, C. 2008. The Structuring of Feeling in Ghanaian Transnational Families. City and Society 2,20: 222 - 250. https://doi.org/10.1111/j.1548-744X.2008.00018.x

Hlatshwayo, M. \& S. Vally 2014. Violence, Resilience and Solidarity: The Right to Education for Child Migrants in South Africa. School Psychology International 35,3: 266 - 279.

https://doi.org/10.1177/0143034313511004

Laczko, F. 2005. Migration and Development: Current Policy Challenges. In Manuh, T. (ed.): At Home in the World? International Migration and Development in Contemporary Ghana and West Africa. Accra: SubSaharan Publishers, Legon.

McKenzie, D. 2011. Can Migration Reduce Educational Attainment? Evidence from Mexico. London: University College.

Page, J. \& R. Adams 2005. The Impact of International Migration and Remittances on Poverty. In Maimbo, S.M. \& D. Ratha (eds): Remittances:

Development Impact and Future Prospects. Washington D.C.: The World Bank.

Quartey, P. 2006. Impact of Migrant Remittances on Household Welfare in

Ghana. (AERC Research Paper 158.) Nairobi: African Economic Research Consortium.

Reyes, M.M. 2007. Filipino Children Left Behind: A Literature Review. Cambridge: UNICEF.

Rossi, A. 2008. The Impact of Migration on the Children in Developing Countries, Cambridge. Cambridge: Harvard University Kennedy School of Government.

Rossi, A., E. Jesperson \& R. Saab 2002. Children, Youth and Migration. The Challenges. Cambridge: UNICEF.

Skelton, A. \& K. Ngidi 2014. Unaccompanied Foreign Migrant Children in 
South Africa. Pretoria: Human Sciences Research Council.

Suárez-Orozco, C., I.L.G. Todorova \& J. Louie 2002. Making Up for Lost Time: The Experience of Separation and Reunification among Immigrant Families. Family Process 41,4: 625 - 643.

https://doi.org/10.1111/j.1545-5300.2002.00625.x

PMid:12613121

Whitehead, A. \& A. Hashim 2005. Children and Migration. Sussex: Development Research Centre on Migration.

Yeoh, S. \& T. Lam 2006. The Costs of (Im)Mobility: Children Left Behind and Children who Migrate with a Parent. Conference paper. UNESCAP. Available at:

https://www.unescap.org/sites/default/files/SDD_PUB_Perspectives_on _Gender_and_Migration.pdf

Dr. Beatrice Okyere-Manu Senior Lecturer

Programme Director for Applied Ethics School of Religion, Philosophy and Classics University of KwaZulu-Natal Pietermaritzburg okyere-manv@ukzn.ac.za

Prof. Herbert Moyo

Practical Theology

School of Religion, Philosophy and Classics University of KwaZulu-Natal Pietermaritzburg moyoh@ukzn.ac.za 